\title{
A GIS tool for land and water use planning in mining regions
}

\author{
Alex Mark Lechner ${ }^{a}$, Neil McIntyre ${ }^{b}$, Nena Bulovic ${ }^{b}$, Heini Kujala $^{c}$, Amy Whitehead ${ }^{c}$, \\ Anthony Webster ${ }^{\mathrm{d}}$, Brendan Wintle ${ }^{\mathrm{c}}$, Will Rifkin ${ }^{\mathrm{a}}$ and Margaretha Scott ${ }^{\mathrm{d}}$ \\ ${ }^{a}$ Centre for Social Responsibility in Mining, Sustainable Minerals Institute, \\ The University of Queensland, Brisbane, QLD, 4072 AUSTRALIA, \\ ${ }^{b}$ Centre for Water in the Minerals Industry, Sustainable Minerals Institute, \\ The University of Queensland, Brisbane, QLD, 4072 AUSTRALIA, \\ ${ }^{c}$ Centre of Excellence for Environmental Decisions, The University of Melbourne, Australia, \\ ${ }^{d}$ WH Bryan Mining \& Geology Research Centre, Sustainable Minerals Institute, \\ The University of Queensland, Brisbane, QLD, 4072 AUSTRALIA \\ Email:a.lechner@uq.edu.au
}

\begin{abstract}
Mineral rich regions can pose particular land use planning challenges due to economic pressure to mine that can face strong opposition from those concerned about social and environmental impacts. While fundamentally opposing values cannot easily be resolved, progress has been made in developing GIS planning tools that provide a common ground for analysis of scenarios and options. However, the complexity of integrating models across disciplines such as hydrology and ecology poses a considerable challenge.
\end{abstract}

This paper describes a GIS tool that highlights priority areas for biodiversity conservation and water provisioning services and then integrates both to characterize water provisioning ecosystem services (WPES). Biodiversity conservation priority areas were modelled with the spatial prioritization tool Zonation, and water provisioning services were assessed based on runoff, flow path length and the presence of vegetation. Zonation produces prioritisation in a balanced manner that maximises high quality habitats for all biodiversity features (e.g. species) in accordance to their rarity. The top priorities typically represent the full range of regional biodiversity within a relatively small area. These priorities were derived from spatial data describing the distribution of biodiversity features, including flora and fauna species and endangered ecological communities. Water provisioning services were calculated through modelling flow length with a digital elevation model in combination with runoff and spatial data on vegetation cover. Areas with longer flow length, in areas with higher runoff and vegetation cover, have higher values for water provisioning services. Spatial data for biodiversity and water provision services were then combined using a stream network to characterize the value of runoff generating areas in terms of their contribution to downstream riparian biodiversity.

A case study of land use planning in the Greater Hunter region, a mining and agricultural area of New South Wales, Australia, is used to demonstrate our approach to quantifying WPES. The impacts of potential future locations of surface coal mining were assessed by examining the spatial overlap of a coal seam geological layer with WPES. Our analysis identified areas that have high WPES value that may be affected by mining in the future. The aim of this research is not to present an end-point for a planning process but to demonstrate the value of and ways forward for incorporating system interactions by combining outputs of modelling tools. We conclude by discussing future research and the challenge of considering jointly water impacts and biodiversity impacts, including the need to evaluate interactions among the various GIS layers.

Keywords: Mining, resource extraction, integrative modelling, strategic environmental assessment, cumulative impacts, land use planning 


\section{INTRODUCTION}

In mineral rich regions, there is a need for tools that facilitate ways to reach a common vision for future land use among multiple stakeholders with input from multiple areas of scientific expertise. At the very least, one needs a common and objective understanding of the key factors for land use planning and their interactions. Quantitative assessment methods for regional land use planning in mining regions ideally aim to address the cumulative dimension of impacts that result from successive, incremental and combined impacts (positive and negative) on the environment, society and economy. The impacts from a single mine may be small regionally, but successive mine developments over time from one or more mines can result in the degradation of important resources (Franks et al., 2013). Positive and negative impacts in mining regions reflect the effects of activities in different economic sectors, drawing on different forms of capital: natural, social, human, financial and manufactured.

Achieving the objective of a shared vision benefits from decision making using an integrative, systems-based approach that can characterize the trade-offs between competing land uses and the linkages between different system components characterised by different disciplines (Hamilton et al., 2015). However, the complexity of integrating across disciplines that typically use a range of modelling approaches - as required in planning for mining development - poses a considerable challenge. To make headway, we start here with two critical system components commonly assessed for regional planning - biodiversity and water. These components can be considered separately, but they also interact, such as in riparian areas. These riparian areas are important for instream and adjacent biodiversity and are affected by upstream processes and provide ecosystem services downstream (Bennett et al., 2014; Nilsson and Svedmark, 2002; Sabo et al., 2005).

The Greater Hunter Region, approximately $100 \mathrm{~km}$ north of Sydney, Australia, covers a total area of 34,850 $\mathrm{km}^{2}$, approximately the size of the landmass of the Netherlands. In this region, economically viable coal seams are found in urban areas, farmlands, and floodplains, mountain ranges and coastal environments. These areas often have multiple other landscape uses, including biodiversity, water resources, agricultural and tourism value. These values can be negatively affected by coal mining, both surface and underground mining methods (Lechner et al., 2014). The region is the most populated area outside Sydney in NSW, and it has been identified as a future area for the expansion of coal mining. It is expected to see a high level of population growth resulting in increasing pressure on the environment and competition with high productivity agriculture, such as vineyards and horse breeding (NSW Department of Planning, 2005). The region is therefore an excellent setting to explore advances in land use planning tools.

In this paper, we use the Greater Hunter as a case study to describe a land use planning approach for integrating biodiversity and water values. The new contribution of this work is its exploration of how to consider interactions between system components - biodiversity and water in this case - as well as considering the independent values attached to each. We first conduct a short review on the links between surface water, riparian health and terrestrial biodiversity. Then we model biodiversity values using Zonation, a spatial prioritization tool for ranking locations based on their priority for conservation. Next we develop a simple index for assessing the importance of any location within a catchment for downstream water provisioning services. Finally, we integrate both models by adjusting the water provisioning index based on the downstream riparian biodiversity to assess water provisioning ecosystem services (WPES). We conclude by discussing the implications for regional planning, the potential for building more complexity into the models while retaining a practical and transparent approach.

\section{REVIEW OF SURFACE WATER, RIPARIAN HEALTH AND TERRESTRIAL BIODIVERSITY}

The riparian zone provides numerous ecosystem services. It can have an important role in regulating the exchanges of water, energy and nutrients between the terrestrial, groundwater, air and surface water environments as it: i) supplies woody debris to support in-stream and riparian habitat; ii) provides physically stable environments to moderate erosion; iii) distributes water and nutrients through catchments; iv) contributes to functioning of flood plains; v) and provides flow resistance to diffuse flood flow intensity. Riparian zones also have important roles for biodiversity providing shelter and access to food and water for fauna and as corridors linking land areas of high biodiversity. Riparian zones are important for biodiversity by supporting different species to those found in adjacent habitats (Sabo et al., 2005), providing habitat for terrestrial species especially in highly modified environments (e.g. Bennett et al., 2014) and influencing instream aquatic fauna and flora abundance and diversity (e.g. Magierowski et al., 2012). The health of the riparian zone, and how it interacts with terrestrial biodiversity, are therefore important when considering potential land use impacts on water (Nilsson and Svedmark, 2002). 
Riparian condition is strongly linked to the river flow and channel condition, although also affected by riparian zone management, and interactions with the surrounding landscape, atmosphere and groundwater (Nilsson and Svedmark, 2002). The river properties affecting riparian health include flow rates and their variability, water chemistry, biology, river bed composition, and sediment type, budget and chemistry.

Indexing the health of a river ecosystem and integrating ecological data typically involves determining the regionally or locally relevant physical, chemical and biological indicators, and classifying the condition or predicted impacted condition relative to a target condition. Guidelines for doing this are available in many regions, and routinely applied for impacts assessment of projects involving significant land and/or water use change. For example, the impacts assessment of a mining project in Australia includes assessment of regionally relevant physical, chemical and biological impacts on waterways (e.g. NSW Department of Planning, 2005).

\section{METHODS}

\subsection{Biodiversity mapping}

The spatial prioritization tool Zonation was used to identify priority areas for conservation (Moilanen et al., 2013). It produces a ranked prioritization of the landscape using spatial data on the distribution of biodiversity features in sites (grid cells), starting first by assuming that the whole landscape is protected, and then iteratively removing the least valuable remaining cell while accounting for generalized complementarity. The prioritisation is produced in a balanced manner that maximises high quality habitats for all species in accordance to their rarity. The top priorities (top ranked grid cells) typically represent the full range of regional biodiversity within a relatively small area.

In the Greater Hunter the Zonation assessment included data for a range of biodiversity features, including flora and fauna species, and endangered ecological communities (Kujala et al., 2015). 653 species with more than 20 occurrence points identified from publically available data (www.ala.org.au) within the Greater Hunter were used to produce continuous distribution maps showing the likelihood of observing a species in any grid cell (100 m size). The species distribution modelling tool Maxent was used to model likelihood of occurrence with the occurrence data and environmental data (Phillips et al., 2006). The environmental data included: temperature, rainfall, solar radiation, altitude, slope, aspect, terrain, wetness, vegetation and soils. Cleared areas were removed from the distribution maps using additional vegetation mapping data.

\subsection{Water provisioning services}

An index of the value of water provisioning services generated for each $100 \mathrm{~m}$ grid cell within the study area was calculated as a function of Flow length $[\mathrm{km}] \times \operatorname{Runoff}[\mathrm{m}] \times$ Vegetation $\left[\mathrm{km}^{2}\right]$, where:

- Flow length is the downstream surface flow path length. The logic behind this parameter is that a unit of water is likely to generate more value on a longer flow path due to servicing a larger number of users.

- Runoff is the estimated long-term surface runoff. The logic behind this parameter is that a grid cell generating more water generates more value along its flow path downstream as opposed to a cell that is nearly dry.

- Vegetation index categorises land according to whether it is cleared or not. The logic behind this parameter is that the clearing of vegetation for other land uses is commonly directly correlated with reduced downstream water quality (Sonter et al., 2013), e.g. due to erosion, nutrient loads and changes in natural flow regimes.

The Shuttle Radar Topography Mission (SRTM) 1 arc-second global DEM and digitized stream lines from existing hydrological spatial data (NSW Government) were used to calculate flow lengths for each pixel in the Greater Hunter Region. The DEM was resampled to the same resolution as the biodiversity mapping outputs, after which it was hydrologically conditioned and flow lengths were determined using the ESRI ArcGIS Spatial Analyst (Hydrology) toolset.

Long term average annual runoff was derived from existing CSIRO AWAP runoff spatial data (Raupach et al 2009) at $5 \mathrm{~km}$ resolution, using annual time steps for the period of 1961 to 1990 . The CSIRO AWAP data does not extend to the eastern edge (coast) of the Greater Hunter Region study area, so the missing data was interpolated using Inverse Distance Weighting approach.

Vegetation was categorized as either cleared [0] or intact [1] using a combination of the best available NSW vegetation mapping in the Greater Hunter. 


\subsection{Integrating biodiversity and water provisioning services to assess water provisioning ecosystem services}

The above two modelling methods were then combined to assess WPESs by adjusting the water provisioning services index based on the downstream riparian biodiversity values characterized by the Zonation outputs. The final output is a raster dataset of WPES values that can be used to identify priority areas for protection.

Regions of riparian biodiversity were defined as those locations where the Zonation biodiversity pixels and the DEM-derived stream network overlapped. The DEM-derived streams were delineated as those with a contributing catchment of at least $50 \mathrm{~km}^{2}$, thus placing emphasis on larger streams rather than small and potentially ephemeral drainage channels. The riparian biodiversity value (RBV) was then calculated as a property of the Zonation prioritization (percentile) ranking and rescaled based on the number of intact catchment pixels and runoff contributing to each cell. Rescaling RBVs is a means of explicitly incorporating contributing catchment characteristics and accounting for the relative importance of each upslope pixel to the RBV. For example, two points on a stream (i and ii - Figure 1a) have the same RBV but the catchment of point $i$ is three times that of point ii. As such, each pixel in catchment ii contributes approximately three times more unit 'value' to its respective riparian biodiversity compared to catchment $i$, which is captured by the rescaled RBV.

WPES for each cell in the study area was then calculated as: Runoff $\times \sum$ (Downstream Rescaled RBV $\times$ Flow length). For example, the runoff generated by pixel iii flows downstream through riparian pixels $i$ and ii thus contributing to both pixels' RBVs (Figure 1b). As such, pixel iii's WPES is equal to the generated runoff $x$ cumulative sum of rescaled RBV weighted by flow length for all riparian biodiversity points ( $i$ and ii) on the flow path.
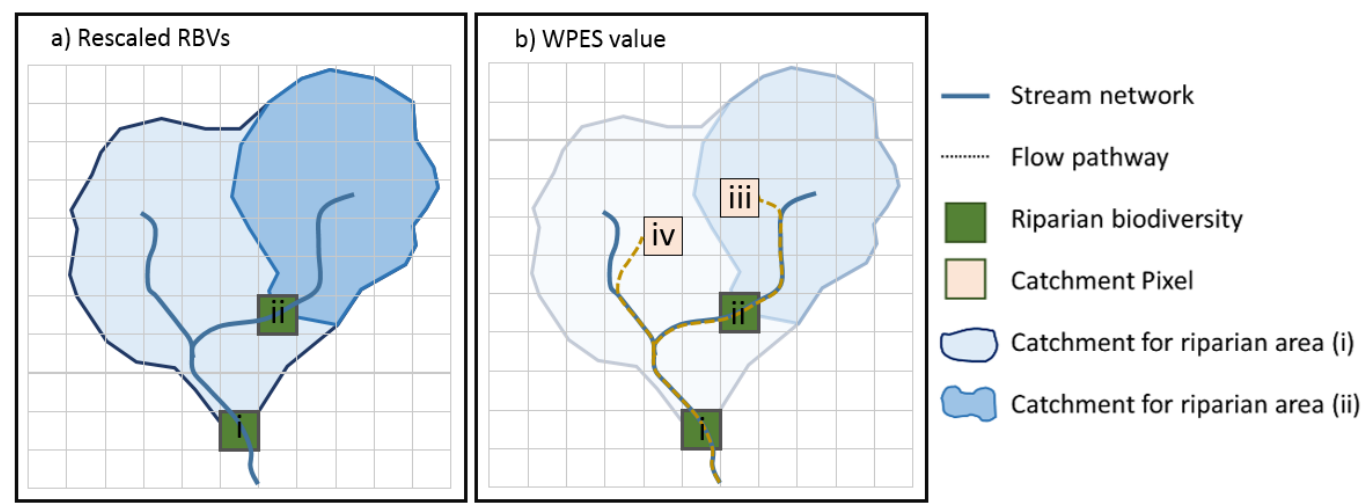

Figure 1. a) Riparian biodiversity value (i, ii) was rescaled by total intact catchment area. b) WPES for any pixel in the catchment was calculated based on the downstream biodiversity and pixel runoff.

\subsection{Surface coal mining potential}

Using existing geology layers of the Sydney Basin (Colquhoun et al., 2015), expert knowledge and the location of existing and future planned mines, we derived a GIS layer for potential future coal mining. The coal mining potential layer is based on the assumption that economic deposits of coal in the Upper Hunter Valley occur as seams within well-defined sedimentary strata. The host strata are often referred to as 'coal measures' and mapped as such. Based on the overlap of current and planned surface coal mines identified by NSW spatial data, we found that only rocks from the Permo-Triassic age were potential host rocks. The potential location of underground coal mines was less clear than with surface mining, and thus we excluded the Newcastle and Illawara coal measures from our analysis. If mining is undertaken within these areas identified by the coal seams, likely mining-related impacts will include the mine pit, waste-dump placement, and transport and washery infrastructure.

\section{RESULTS}

Figure 2a shows Zonation's ranking of biodiversity priorities based on species distribution modelling. High biodiversity priorities were found along the coastline and in the fragmented valley floor running from north to south of the central region in the Greater Hunter. Figure 2b shows the location of areas ranked high in water provisioning services, which were found in the headwaters of the Greater Hunter toward the northwest and also in a central region in the high elevation Barrington Tops National park. 


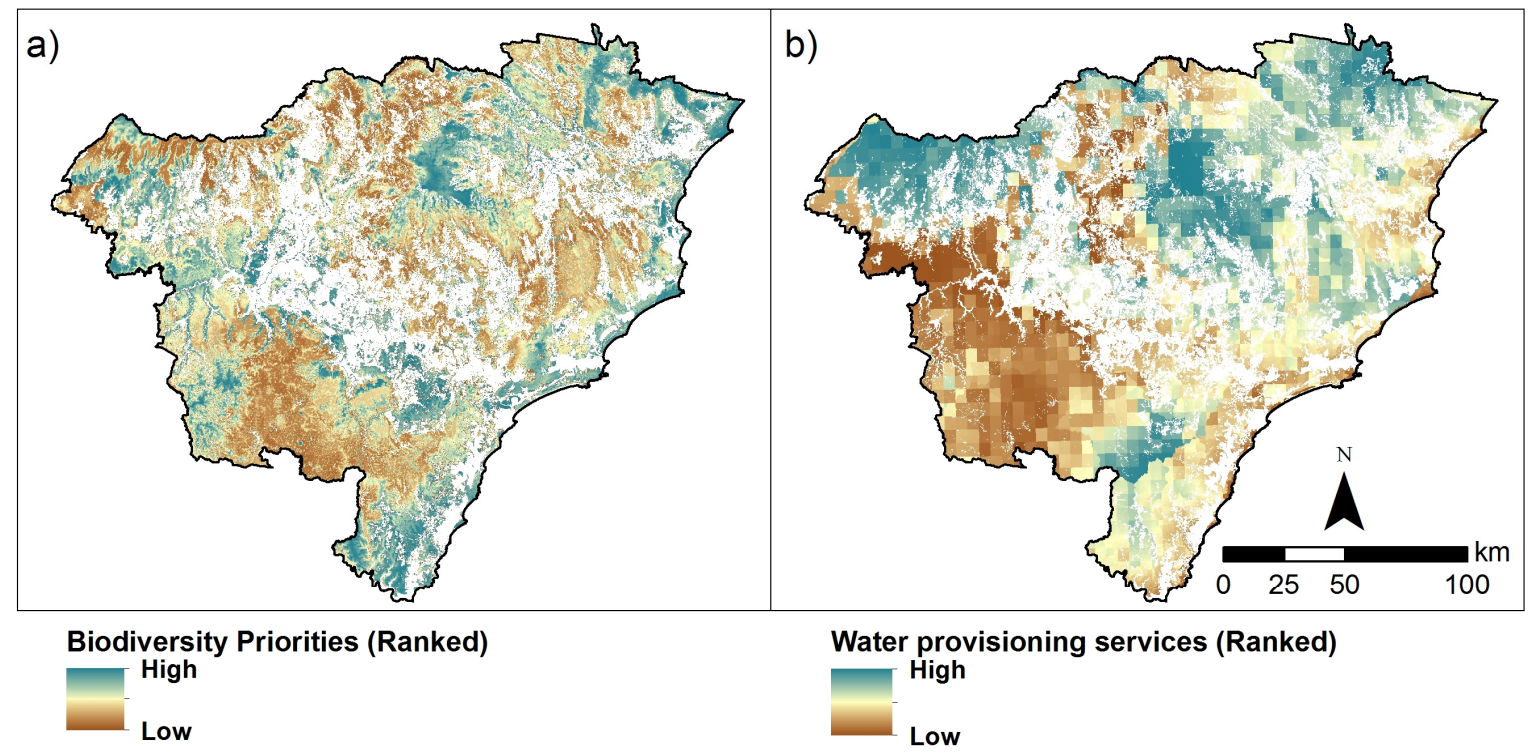

Figure 2. a) Biodiversity priorities based on Zonation. b) Water provisioning services based on flow length, runoff and presence/absence of vegetation. White regions represent cleared land.

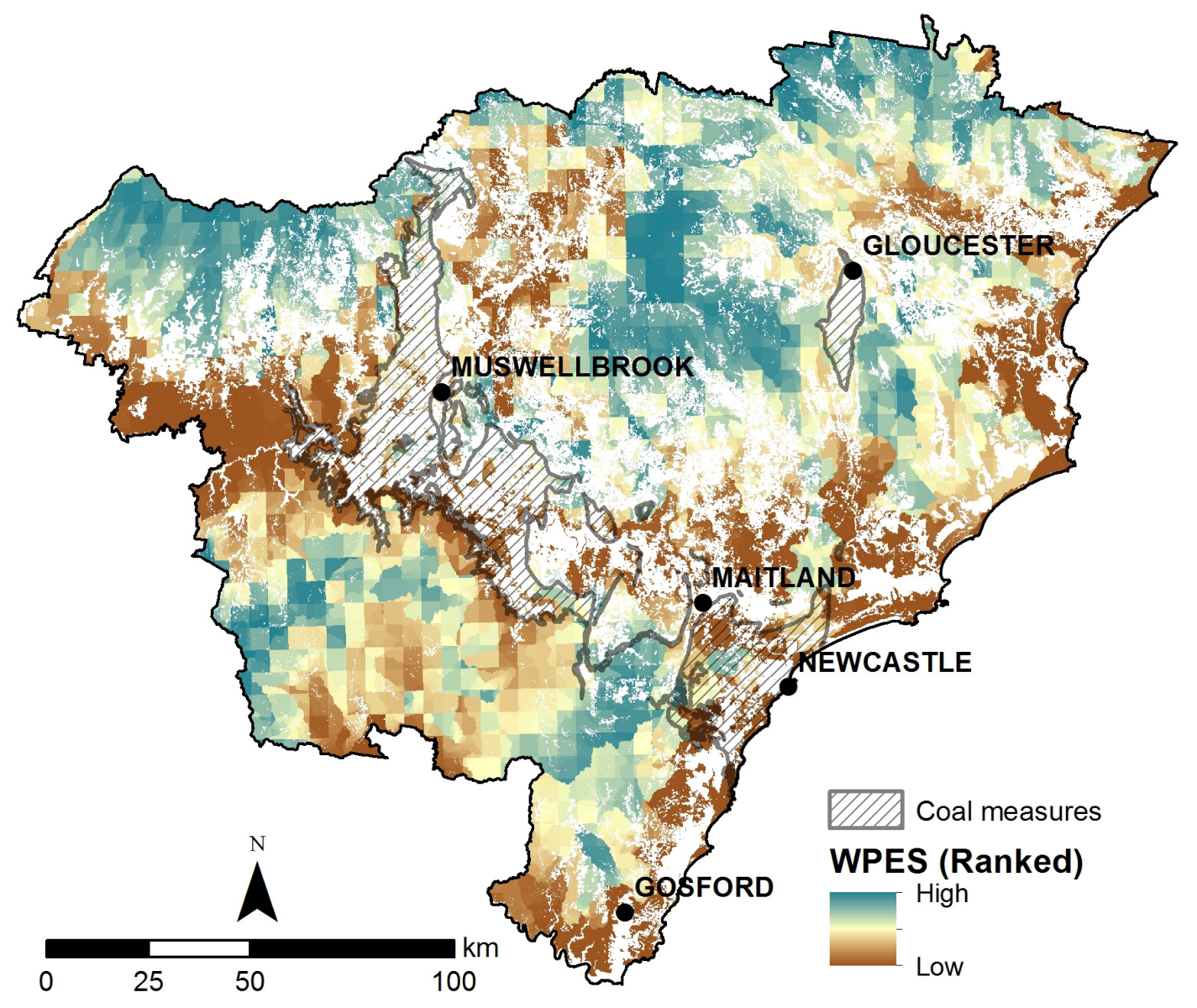

Figure 3. WPES ranked (normalized) based on importance for downstream biodiversity and runoff. White regions represent cleared land.

The combined WPES ranked outputs (Figure 3) revealed highest values for the headwaters in the northwest and the Barrington Tops National park central region between Muswellbrook and Gloucester. An overlay of the coal measures geological layer, which describes areas where future mining may take place, shows that the 
majority of vegetation in this area is already cleared and fragmented. The addition of the generally lower runoff generation capacity in this area, and the lower downstream flow length, leads to a lower WPES values.

\section{DISCUSSION}

Tools for regional land use planning need appropriate generalizations and simplifications to enable assessment of broad scale priorities. In the case of strategic environmental assessments that are undertaken for approving and planning multiple developments in a region (Noble et al., 2012), such as in the Hunter (NSW Department of Planning, 2005), a range of GIS modelling methods are often used. Our approach represents one method for conducting a robust assessment by integrating regional scale data and methods across disciplines, in this case biodiversity and hydrology. The potential biodiversity service provided by an area of land was based on a sophisticated spatial prioritization tool that can be considered leading practice, Zonation; and the potential hydrological service provided by an area of land was based on its downstream contribution to flows and riparian biodiversity.

Justifying a particular method of quantifying ecosystem services is problematic especially when different (perhaps equally good) approaches and assumptions give results that are favourable for different stakeholders; and this may be a particular challenge when addressing complex system interactions (water and biodiversity in our case). It is not necessary that the most complex approach be used in every case - it may not be the most scientifically justified given the uncertainties involved, or the most practical for running scenarios and testing sensitivity to assumptions. Our modelling method utilized a normative, simple approach for proposing areas that are a priority for protection from mining through overlaying future mining areas with WPES priorities. These normative (high versus low) values can form the basis for a stakeholder-based, explicit quantification of trade-offs between values (Mendoza and Prabhu, 2005) through converting rankings to stakeholder preferences.

The current modelling methods presented in this paper should be further improved, and the sensitivity of the parameterisation, model choice and the impact of spatial data uncertainty need to be assessed (Lechner et al., 2012). Further refinement would include: i) investigating other available datasets and improving stream definition through more robust techniques (e.g. Tarboton, 1997); ii) including a buffer zone around streams; iii) addressing the limitations to runoff modelling such as coarse spatial scale, large temporal time-step, simple water balance model developed for the entire country; iv) considering groundwater recharge and groundwater flow pathways; v) incorporating soil, geology and the influence of land use on water quality; and vi) ranking biodiversity conservation value downstream based on potential impact of changes in water values.

While recognizing the need to refine the metrics used, some results of interest were found. Little overlap was noted between high WPES values and potential future mining due to the existing relatively low contribution of these areas to quantity and quality of downstream flows. In contrast, when examining the location of biodiversity priorities only, the central region of fragmented flood plains where mining occurs is made of mostly high value biodiversity pixels found in small patches (Figure 2a). So, while there is limited apparent conflict between WPES values and mining values, there does appear to be a greater conflict between biodiversity values and mining values.

\section{CONCLUSION}

Numerous models and tools can be drawn upon to assess impacts from mining at the regional scale. These methods need to consider the cumulative, social and environmental impacts of mining and the trade-offs with competing land use values. The aim in this paper was not to present an end-point for a planning tool but to demonstrate the value of and ways forward for incorporating system interactions. While tools and techniques can be drawn from the multiple disciplines that are required for any assessment of mining impacts - from geochemistry to landscape ecology - there are few examples of integration. Trade-offs between the range of landscape values impacted by mining and positive non-spatial impacts (e.g., economic benefits) can be addressed through interdisciplinary modelling approaches such as presented in this paper.

\section{ACKNOWLEDGMENTS}

Thanks to Beverly Kubat and Alan Cocker for their input. This publication was supported by the University of Queensland post-doctoral fellowship and the NextMine Common Ground project. 
Lechner et al., A GIS tool for participatory land and water use planning in mining regions

\section{REFERENCES}

Bennett, A. F., Nimmo, D. G., and Radford, J. Q. (2014). Riparian vegetation has disproportionate benefits for landscape-scale conservation of woodland birds in highly modified environments. Journal of Applied Ecology, 51(2), 514-523.

Colquhoun, G. P., Phillips, G., Hughes, K. ., Deyssing, L., Fitzherbert, J. A., and Troedson, A. 1. (2015). New South Wales Zone 56 Seamless Geology dataset, version 1 [Digital Dataset].

Franks, D. M., Brereton, D., and Moran, C. J. (2013). The cumulative dimensions of impact in resource regions. Resources Policy, 38(4), 640-647.

Hamilton, S. H., ElSawah, S., Guillaume, J. H. A., Jakeman, A. J., and Pierce, S. A. (2015). Integrated assessment and modelling: Overview and synthesis of salient dimensions. Environmental Modelling \& Software, 64, 215-229.

Kujala, H., Whitehead, A., and Wintle, B. . (2015). Identifying conservation priorities and assessing impacts and trade-offs of potential future development in the Lower Hunter Valley in New South Wales. A report by the NERP Environmental Decisions Hub.

Lechner, A. M., Baumgartl, T., Matthew, P., and Glenn, V. (2014). The impact of underground longwall mining on prime agricultural land: a review and research agenda. Land Degradation \& Development. DOI: $10.1002 / \mathrm{ldr} .2303$

Lechner, A. M., Langford, W. T., Bekessy, S. A., and Jones, S. D. (2012). Are landscape ecologists addressing uncertainty in their remote sensing data? Landscape Ecology, 27(9), 1249-1261.

Magierowski, R. H., Davies, P. E., Read, S. M., and Horrigan, N. (2012). Impacts of land use on the structure of river macroinvertebrate communities across Tasmania, Australia: Spatial scales and thresholds. Marine and Freshwater Research, 63(9), 762-776.

Mendoza, G. A., and Prabhu, R. (2005). Combining participatory modeling and multi-criteria analysis for community-based forest management. Forest Ecology and Management, 207(1-2 SPEC. ISS.), 145156.

Moilanen, A., Meller, L., Leppänen, J., Pouzols, F. M., Arponen, A., and Kujala, H. (2013). Spatial conservation planning framework and software Zonation v.3.1 User manual. Helsinki: University of Helsinki.

Nilsson, C., and Svedmark, M. (2002). Basic principles and ecological consequences of changing water regimes: Riparian plant communities. Environmental Management, 30(4), 468-480.

Noble, B. F., Gunn, J., and Martin, J. (2012). Survey of current methods and guidance for strategic environmental assessment. Impact Assessment and Project Appraisal, 30(3), 139-147.

NSW Department of Planning. (2005). Coal Mining Potential in the Upper Hunter Valley -- Strategic Assessment, (December).

Phillips, S. J., Anderson, R. P., and Schapire, R. E. (2006). Maximum entropy modeling of species geographic distributions. Ecological Modelling, 190(3-4), 231-259.

Raupach, M. R., Briggs, P. R., Haverd, V., King, E. a., Paget, M., and Trudinger, C. M. (2009). Australian Water Availability Project (AWAP): CSIRO Marine and Atmospheric Research Component: Final Report for Phase 3.

Sabo, J. L., Sponseller, R., Dixon, M., Gade, K., Harms, T., Heffernan, J., Jani, A., et al. (2005). Riparian zones increase regional species richness by harboring different, not more, species. Ecology, 86(1), 5662 .

Sonter, L. J., Moran, C. J., and Barrett, D. J. (2013). Modeling the impact of revegetation on regional water quality: A collective approach to manage the cumulative impacts of mining in the Bowen Basin, Australia. Resources Policy, 38(4), 670-677.

Tarboton, D. G. (1997). A new method for the determination of flow directions and upslope areas in grid digital elevation models RID G-8972-2011. Water Resources Research, 33(2), 309-319. American Geophysical Union. 